\title{
Utilization of Activated Carbon Prepared from Pumpkin Seed Shell for the Removal of Dyestuff from Aqueous Solutions and Wastewater by Microwave Radiation
}

\author{
Ilknur Demiral \\ Department of Chemical Engineering, Faculty of Engineering and Architecture, Eskisehir Osmangazi \\ University, Eskisehir, Turkey \\ E-mail:idemiral@ogu.edu.tr \\ Tijen Ennil Bektas \\ Department of Chemical Engineering, Faculty of Engineering, Canakkale Onsekiz Mart University, \\ Canakkale, Turkey \\ E-mail:ennilbektas@comu.edu.tr \\ Canan Aydin Samdan \\ Department of Chemical Engineering, Faculty of Engineering and Architecture, Eskisehir Osmangazi \\ University, Eskisehir, Turkey \\ E-mail:caydin@ogu.edu.tr
}

\begin{abstract}
In this study, the aim was to investigate the removal of the cationic (Methylene Blue, MB) and anionic (Acid Blue 193, AB) dyestuff from aqueous solutions and wastewater (synthetic) using activated carbon prepared from pumpkin seed shell as adsorbent (as catalyst) by the microwave-assisted (MW) method. This process is the combination of MW irradiation, MW adsorbent (as catalyst) and oxidant. The effects of radiation time, dosages of adsorbent and oxidant and initial dyestuff concentration on the removal efficiency were investigated. With the initial dyestuff concentration of $100 \mathrm{mg} / \mathrm{L}$, a $99 \%$ dyestuff removal percentage was obtained applying low power in 3 min using $0.2 \mathrm{~g}$ activated carbon and $0.5 \mathrm{~mL}$ hydrogen peroxide for MB and a 90\% removal percentage was obtained applying low power in 3 min using $0.6 \mathrm{~g}$ activated carbon and $0.5 \mathrm{~mL}$ hydrogen peroxide for $\mathrm{AB}$. Results suggest that the prepared activated carbon from pumpkin seed shell has potential in remediation of dyestuff contaminated waters.
\end{abstract}

Keywords: Activated carbon, Dyestuff, Aqueous solution, Wastewater, Microwave radiation

DOI: $10.7176 / \mathrm{JSTR} / 5-2-08$

\section{Introduction}

Textile, leather, paper, food, printing, plastics and many other industries using dyestuffs consume a large amount of water. As a result, large quantities of colored wastewaters form (Tofighy and Mohammadi, 2014). Due to the chemical structure of dyes and their resistance to light and oxidation, dyestuffs are very difficult to biodegrade in environment. Especially in the textile industry wastewaters having various types of dyestuffs are produced. Basic dyes, acid dyes, reactive dyes, direct dyes, azodyes, mordant dyes, vat dyes, disperse dyes, and sulphur dyes are the most common dyestuffs used in the textile industry (Banerjee et al., 2014). Most of these dyes do not only damage the environment and water, but also have toxic or carcinogenic effects for human health. For this reason, the removal of colorings from wastewater is a very important environmental problem (Faraji et al., 2015). In order to remove dyestuffs, a number of different adsorbents has been used (Dehvari et al., 2017).

Activated carbon is an adsorbent that is used in many areas such as purification of liquids and gases, as a catalyst or assist to a catalyst because of their high adsorption capacity (Angin et al., 2013; Li et al., 2011). Activated carbon is a material with well-developed porous structure with large internal surface area. Having high carbon content and low inorganic compounds is acceptable for preparation of activated carbon (Avelar et al., 2010). The physical and chemical properties of the raw materials, activation

68 | $P$ a g e

www.iiste.org 
method, and activation conditions determine the characteristics of porosity in activated carbons, including pore size distribution, pore shape and surface chemistry (Kılıç et al., 2011; Önal et al., 2007). Activated carbon can be prepared by using physical and chemical activation methods. The former method involves two-step process. First, the raw material is carbonized under high temperatures and inert atmosphere. In the second step, activation was carried out by steam, air or $\mathrm{CO}_{2}$ at higher temperatures (800-1000 $\left.{ }^{\circ} \mathrm{C}\right)$. The later one involves addition of activating reagents i.e. phosphoric acid $\left(\mathrm{H}_{3} \mathrm{PO}_{4}\right)$, sulfuric acid $\left(\mathrm{H}_{2} \mathrm{SO}_{4}\right)$, zinc chloride $\left(\mathrm{ZnCl}_{2}\right)$, potassium hydroxide $(\mathrm{KOH})$, potassium carbonate $\left(\mathrm{K}_{2} \mathrm{CO}_{3}\right)$ to raw material. Then the absorbed material is subjected to thermal decomposition at inert atmosphere and at reasonable temperatures (Gerçel et al., 2007). The chemical activation technique has several advantages compared to the physical activation technique. It requires lower activation temperatures and less activation times. Just in a single step activated carbon is obtained in high yields with a large surface area and well developed microporosity (Kılıç et al., 2011; Yorgun and Y1ldız, 2015; Yang and Qiu, 2010). Unfortunately, this method is costly due to usage of the activating agents. During this process some impurities are produced and require intense washing to remove them. Activated carbon obtained by using $\mathrm{ZnCl}_{2}$ is the most widely used adsorbent for the removal of dyestuff from wastewater because it has an excellent high surface area and high adsorption capacity for organic compounds (Yang and Qiu, 2010).

In recent years, microwave (MW) irradiation has been used for the removal of various organic pollutants (Anton et al., 2016; Lin et al., 2009; Lin et al., 2010; Lai et al., 2006; Wang and Wang, 2016). The most important advantage of microwave radiation is fast heating and high energy efficiency. The non-ionizing electromagnetic waves are in the range of frequency $300 \mathrm{MHz}$ to $300 \mathrm{GHz}$ (Jiang et al., 2016). The chemical bonds of many organic compounds are difficult to break by these electromagnetic waves. In order to increase the treatment efficiency MW irradiation process requires a catalyst and an oxidant (Remya and Lin., 2011).

In this study, the activated carbon obtained from pumpkin seed shell by using a chemical activation method has been investigated as an MW adsorbent. The resultant carbons and oxidant were used to remove dyestuff from wastewater by MW radiation. The effects of radiation time, dosage of adsorbent and oxidant and initial dyestuff concentration of wastewater on the removal efficiency were investigated.

\section{Material and Method}

\subsection{Materials}

The pumpkin seed shells were obtained from pumpkin seed process waste of Peyman Company in Eskişehir, Turkey. The pumpkin seed shells were dried and then crushed by a high-speed rotary cutting mill. Later they were sieved to obtain $0.850 \mathrm{~mm}$ to $1 \mathrm{~mm}$ grain size to use in the next step. Methylene blue and acid blue 193 were obtained commercially (Merck), and used without further purification. Hydrogen peroxide was used as oxidant. All other reagents were analytical grade. As of a MW source we used a domestic microwave oven $(750 \mathrm{~W}, 2450 \mathrm{MHz}$, Vestel) with several power settings.

\subsection{Preparation of the Activated Carbon}

The impregnation ratio of $3 / 1$ and carbonization temperature of $500{ }^{\circ} \mathrm{C}$ were determined as the optimum conditions in a previous study (Demiral et al., 2016). Therefore, these parameters were used in activated carbon preparation.

In this study, zinc chloride $\left(\mathrm{ZnCl}_{2}\right)$ has been used as an activating reagent in the process of chemical activation of pumpkin seed shells. The ratio of $\mathrm{ZnCl}_{2} /$ pumpkin seed shell (w/w) is considered as an impregnation ratio. In the chemical activation process, $\mathrm{ZnCl}_{2}(60 \mathrm{~g})$ was dissolved in distilled water $(200$ $\mathrm{ml}$ ), then the dried, crushed and sieved pumpkin seed shells was added to zinc chloride solution. The resulting mixture was stirred and heated at $75^{\circ} \mathrm{C}$ for $6 \mathrm{~h}$. After the separation of the liquid, the solids were left to the oven at $105^{\circ} \mathrm{C}$ for a day. We have used a stainless steel reactor for the carbonization of the impregnated sample $(10 \mathrm{~g})$. The carbonization process was carried out in a vertical furnace at $500^{\circ} \mathrm{C}$ (heating rate of $10^{\circ} \mathrm{C} / \mathrm{min}$ ) for 1 hour under nitrogen atmosphere (flow rate $100 \mathrm{~mL} / \mathrm{in}$ ). After cooling the activated carbon to room temperature, first it was washed with $0.5 \mathrm{~N} \mathrm{HCl}$ solution, then washed with hot water until the $\mathrm{pH}$ becomes neutral. At last, the wet sample was left to oven for a day at $105{ }^{\circ} \mathrm{C}$ to dry. 


\subsection{Characterization of the Activated Carbon}

In order to measure nitrogen gas adsorption ( $77 \mathrm{~K}$ ), Quantachrome, Autosorb $1 \mathrm{C}$ device was used. The resulting activated carbon initially was degassed at $300^{\circ} \mathrm{C}$ under vacuum for 3 hours. A relative pressure, $\mathrm{P} / \mathrm{P}_{\mathrm{o}}$ in a range of $10^{-5}$ to 1 was collected as the data of adsorption. The Brunauer-Emmett-Teller (BET) equation was utilized for the calculation of the BET surface area from $\mathrm{N}_{2}$ adsorption data. The micropore volume was calculated by using the t-plot method (Demiral et al., 2016). The total pore volume was calculated at a relative pressure of 0.995 .

LECO, CHNS-932 model elemental analyzer has been used to determine the contents of carbon, hydrogen, nitrogen and oxygen for both the pumpkin seed shell and activated carbon. JEOL-JSM5600LV Scanning Electron Microscope (SEM) has been used to determine the surface physical morphology of the activated carbon.

\subsection{Preparation of the Hydrolysed Dyestuff Solution (wastewater)}

The synthetic wastewater used in this study was prepared as follows. $0.1 \mathrm{~g} / \mathrm{L}$ of dyestuff, $30 \mathrm{~g} / \mathrm{L}$ of NaCl and $1.6 \mathrm{~g} / \mathrm{L}$ of $\mathrm{Na}_{2} \mathrm{CO}_{3}$ are taken in a beaker, and added to a sufficient amount of water and $0.4 \mathrm{~mL} / \mathrm{L}$ of $10 \mathrm{M} \mathrm{NaOH}$. The mixture is stirred at $50^{\circ} \mathrm{C}$ for 1 hour. The solution is cooled and then brought to neutral $\mathrm{pH}$ using $12 \mathrm{M} \mathrm{HCl}$. Portable Inolab Model $\mathrm{pH}$-meter was used for measuring the $\mathrm{pH}$ values in the solution. The solution was transferred to a volumetric flask and the volume was completed to $1 \mathrm{~L}$ with distilled water of the same $\mathrm{pH}$ (Morais et al., 1999).

\subsection{Methods}

In the procedure for the studies, a fixed amount of adsorbent and oxidant and $50 \mathrm{~mL}$ of aqueous dyestuff solution or wastewater containing $100 \mathrm{mg} / \mathrm{L}$ dyestuff were mixed in capped volumetric glass flasks and radiated by MW under different conditions. All the samples were filtered and the dyestuff concentrations in the supernatant were measured at 663 and $581 \mathrm{~nm}$ corresponding to the maximum absorbance for MB and $\mathrm{AB}$, respectively, using a UV spectrophotometer (Thermo Electron AquaMate).

In order to achieve the maximum removal of dyestuff by MW radiation, the operation conditions were optimized. Four parameters were investigated: the amount of adsorbent $(0.1-0.6 \mathrm{~g} / 50 \mathrm{~mL})$, the amount of oxidant $(0.1-0.5 \mathrm{~mL} / 50 \mathrm{~mL}$ wastewater), the initial dyestuff concentration $(100-500 \mathrm{mg} / \mathrm{L})$ and the irradiation time (0.5 and 4 minutes).

\section{Results and Discussion}

\subsection{Characterization of Activated Carbon}

In Table 1, we have summarized proximate and ultimate analyses results along with surface properties of the pumpkin seed shell and activated carbon.

The analytical results show that pumpkin seed shell has high carbon and low ash contents indicating that it is a suitable raw material for activated carbon production. Ultimate analyses results show that there is an increase in the carbon content after activation process as we expected. However, the amount of hydrogen, nitrogen and oxygen (wt.\%) is decreased due to elimination of the volatile non-carbon species during carbonization process (Aygün et al., 2003). The specific surface area, total pore volume and micropore volume of the activated carbon were $1564 \mathrm{~m}^{2} / \mathrm{g}, 0.965 \mathrm{~cm}^{3} / \mathrm{g}$ and $0.526 \mathrm{~cm}^{3} / \mathrm{g}$, respectively and the micropore volume percentage of the activated carbon is $56 \%$. Nitrogen adsorption is a standard procedure for the determination of the porosity of carbonaceous adsorbents. Fig. 1 shows the adsorptiondesorption isotherm of $\mathrm{N}_{2}$ at $77 \mathrm{~K}$.

The shape of the adsorption isotherm can provide preliminary qualitative information on the adsorption mechanism and on the porous structure of the carbons (Demiral and Güngör, 2016). The adsorption isotherm of the activated carbon sample produced from pumpkin seed shell was primarily of Type I, characteristic of microporous materials. However, the small hysteresis loops seen on the adsorptiondesorption isotherm of the activated carbon are due to the existence of mesopores (Guo and Rockstraw, 2007).

The surface morphology of the samples was observed by using Scanning electron microscopy (SEM) technique. Fig. 2 illustrates the SEM photograph of pumpkin seed shell and activated carbon obtained at activation temperature of $500{ }^{\circ} \mathrm{C}$ and impregnation ratio of $3: 1$. 
Table 1. Characteristics of the pumpkin seed shell and activated carbon

\begin{tabular}{|c|c|c|}
\hline Characteristics & Pumpkin seed shell & Activated carbon \\
\hline Moisture content (wt.\%) & 7.6 & - \\
\hline \multicolumn{3}{|l|}{ Proximate analysis (wt.\%) } \\
\hline Volatile Matter & 70.9 & - \\
\hline Ash & 3.9 & - \\
\hline Fixed carbon & 17.6 & - \\
\hline \multicolumn{3}{|l|}{ Ultimate analysis $(w t . \%)^{a}$} \\
\hline Carbon & 48.8 & 75.7 \\
\hline Hydrogen & 7.5 & 3.1 \\
\hline Nitrogen & 3.9 & 2.7 \\
\hline Oxygen (by difference) & 39.8 & 18.5 \\
\hline \multicolumn{3}{|l|}{ Surface properties } \\
\hline BET surface area $\left(\mathrm{m}^{2} / \mathrm{g}\right)$ & 7.96 & 1564 \\
\hline Micropore area $\left(\mathrm{m}^{2} / \mathrm{g}\right)$ & - & 878 \\
\hline Total pore volume $\left(\mathrm{cm}^{3} / \mathrm{g}\right)$ & - & 0.965 \\
\hline Micropore volume $\left(\mathrm{cm}^{3} / \mathrm{g}\right)$ & - & 0.526 \\
\hline Mesopore volume $\left(\mathrm{cm}^{3} / \mathrm{g}\right)$ & - & 0.439 \\
\hline Average pore diameter $(\mathrm{nm})$ & - & 2.47 \\
\hline
\end{tabular}

${ }^{a}$ Dry free basis

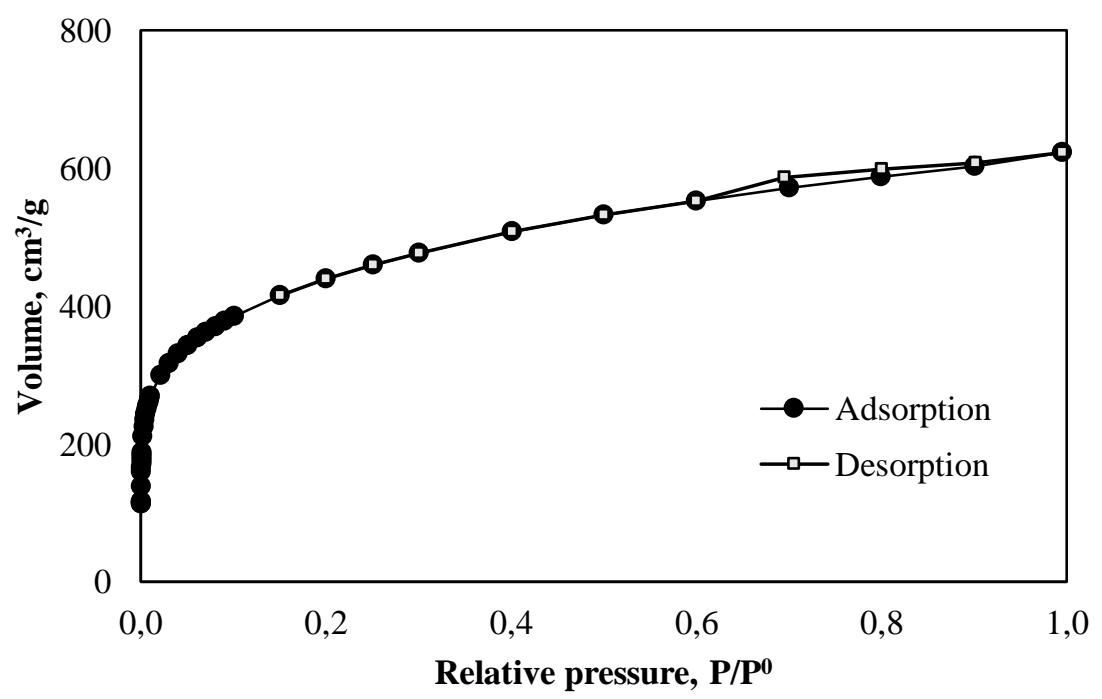

Figure 1.The adsorption-desorption isotherm of the produced activated carbon. 


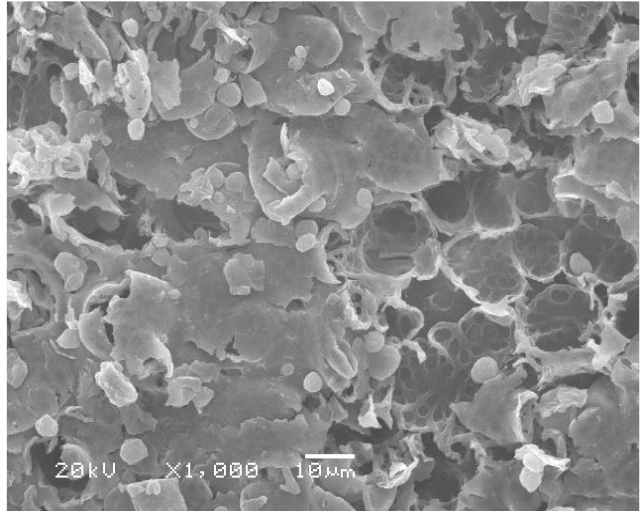

(a)

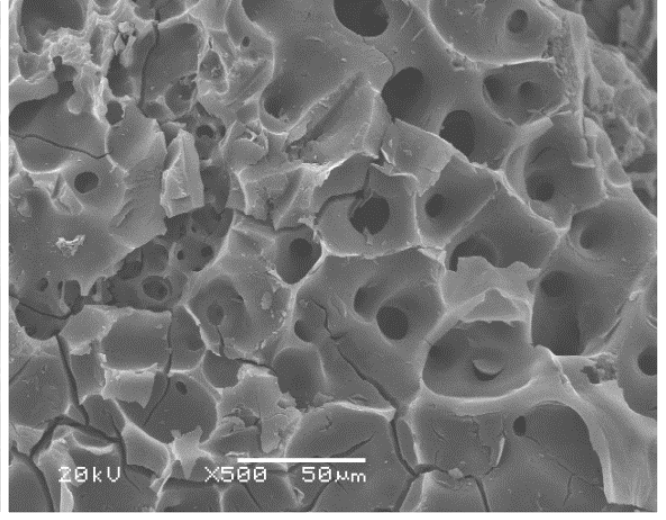

(b)

Figure 2. SEM image of (a) pumpkin seed shell and (b) activated carbon.

From Fig. 2 it is clearly seen that the morphology of the activated carbon is different from the pumpkin seed shell morphology. Quite smooth surface was observed for the pumpkin seed shell except for some occasional cracks, as supported by the BET results $\left(7.96 \mathrm{~m}^{2} / \mathrm{g}\right)$. The surface area of the activated carbon is higher due to remarkable well-developed pore structure. The SEM image of activated carbon shows the existence of full of cavities, different shapes and sizes of the pores. During carbonization process $\mathrm{ZnCl}_{2}$ was removed by evaporation from the cavities on the surface of the activated carbon (Demiral and Demiral, 2008). This resulted having high surface area value in the activated carbon.

\subsection{Effect of Adsorbent and Oxidant Dosage}

The effects of adsorbent and oxidant dosage on dyestuff removal were investigated by addition of different amounts of adsorbent and oxidant into $50 \mathrm{~mL}$ of aqueous solution. The results are shown in Fig. 3 and Fig. 4.

As the amount of adsorbent dosage increases, the number of accessible active centers also increases. As a result, the removal of the dyestuff increases. The dyestuff removal efficiencies of the activated carbon varied approximately from $85 \%$ to $99 \%$ for the adsorbent amounts of 0.1 and $0.5 \mathrm{~g} / 50 \mathrm{~mL}$ MB solution and they varied from $3.5 \%$ to $90 \%$ for the adsorbent amounts of 0.1 and $0.6 \mathrm{~g} / 50 \mathrm{~mL} \mathrm{AB}$ solution, respectively. The optimum amounts of activated carbon were found to be $0.2 \mathrm{~g}$ and $0.6 \mathrm{~g}$ for $\mathrm{MB}$ and $\mathrm{AB}$, respectively. In the experiments performed to investigate the effect of adsorbent dosage without using oxidant, the dyestuff removal efficiencies of the activated carbon were varied approximately from $57 \%$ to $87 \%$ for the adsorbent amounts of 0.1 and $0.5 \mathrm{~g} / 50 \mathrm{~mL} \mathrm{MB}$ solution, and they varied from $7 \%$ to $56 \%$ for the adsorbent amounts of 0.1 and $0.6 \mathrm{~g} / 50 \mathrm{~mL} \mathrm{AB}$ solution, respectively. Because the hydroxyl radicals which cause the breakdown of the dyestuff molecules are formed by the degradation of hydrogen peroxide, the removal of the dyestuff increases as the oxidant concentration increases. The acid blue removal increased as the oxidant concentration was increased while the methylene blue removal remained almost constant. In the experiments performed to investigate the effect of oxidant dosage without adsorbent, the dyestuff removal efficiencies varied approximately from $23 \%$ to $48 \%$ for the oxidant dosage of 0.1 and $0.5 \mathrm{~mL} / 50 \mathrm{~mL} \mathrm{MB}$ solution, and they varied from $31 \%$ to $47 \%$ for the oxidant dosage of 0.1 and $0.5 \mathrm{~mL} / 50 \mathrm{~mL} \mathrm{AB}$ solution, respectively. 


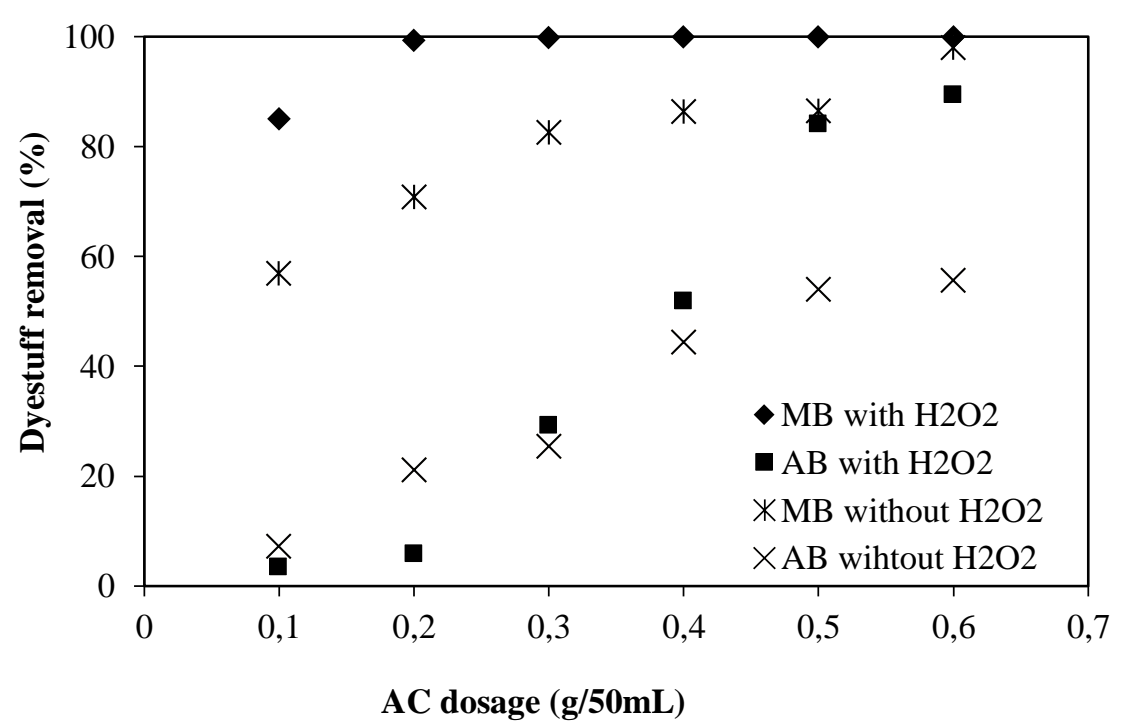

Figure 3. Effect of adsorbent dosage on dyestuff removal with $0.5 \mathrm{~mL}$ oxidant (radiation time: 3 min, initial dye conc: $100 \mathrm{mg} / \mathrm{L}, \mathrm{pH}: 5.65$ for $\mathrm{MB} \mathrm{pH}: 7.2$ for $\mathrm{AB}$ )

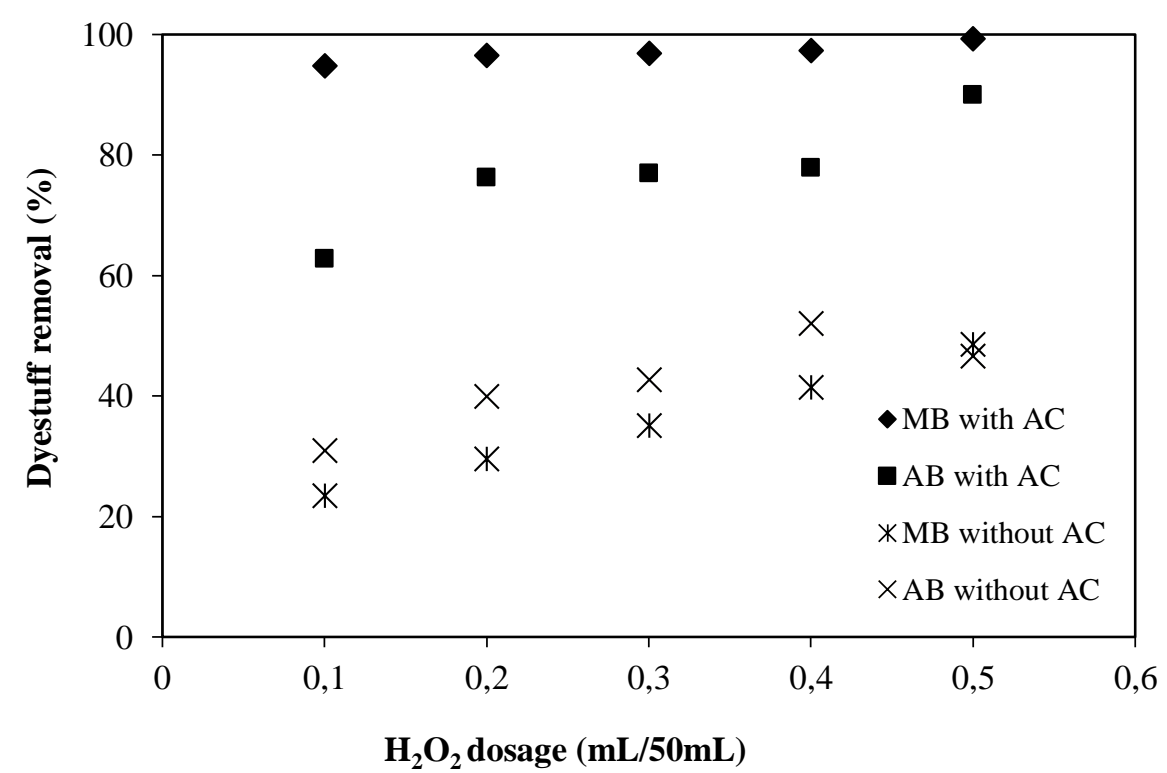

Figure 4. Effect of oxidant dosage on dyestuff removal with fixed amount of activated carbon. (radiation time: $3 \mathrm{~min}$, initial dye :100 mg/L, $\mathrm{pH}: 5.65$ for $\mathrm{MB} \mathrm{pH}: 7.2$ for $\mathrm{AB}$ )

\subsection{Effect of Initial Dyestuff Concentration}

The effects of initial concentration on dyestuff removal are shown in Fig. 5 with varying dyestuff concentration from 100 to $500 \mathrm{mg} / \mathrm{L}$. 


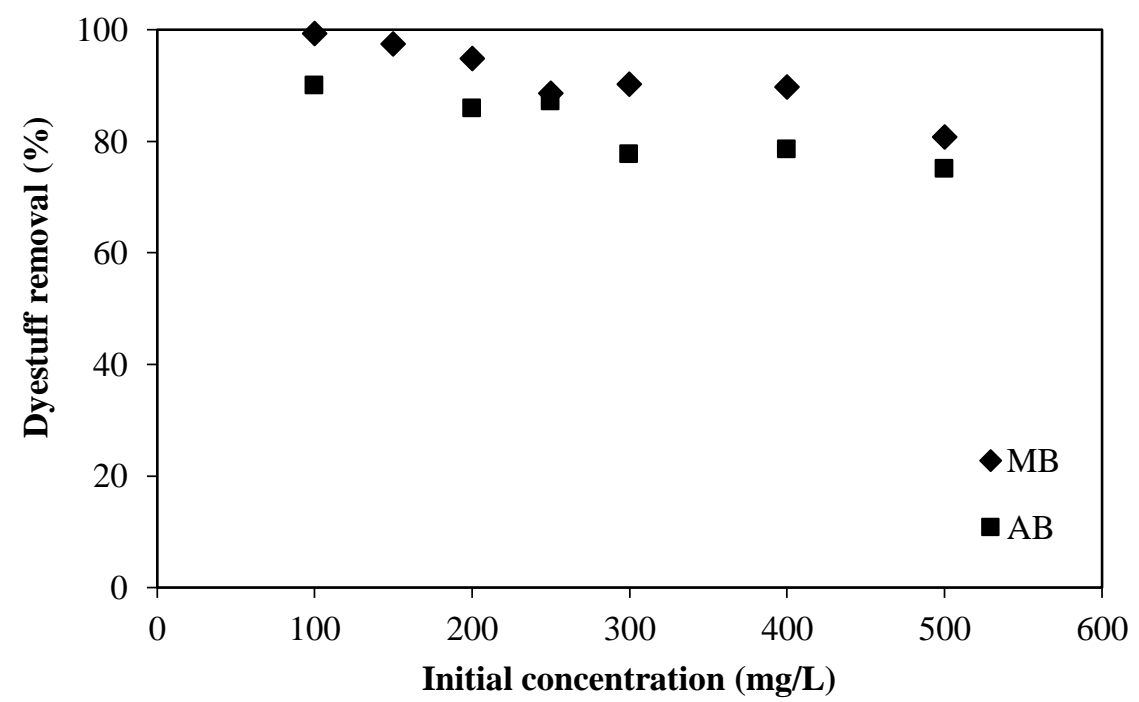

Figure 5. Effect of initial dyestuff concentration on removal with fixed amount of activated carbon and oxidant (radiation time: $3 \mathrm{~min}$, adsorbent dosage: $0.5 \mathrm{~g}$ for $\mathrm{MB} ; 0.6 \mathrm{~g}$ for $\mathrm{AB}$, oxidant dosage: $0.5 \mathrm{~mL}$ for $\mathrm{MB}$ and $\mathrm{AB})$.

The results showed that the removal efficiencies of dyestuff decreased slightly with increasing initial concentration. When the initial concentration was $100 \mathrm{mg} / \mathrm{L}$, the removal efficiencies were $99 \%$ and $90 \%$ for $\mathrm{MB}$ and $\mathrm{AB}$, respectively. When the initial concentration increased to $500 \mathrm{mg} / \mathrm{L}$, the removal efficiencies were decreased to $81 \%$ and $75 \%$ for $\mathrm{MB}$ and $\mathrm{AB}$, respectively. Because the adsorbent contains a number of active centers that are saturated at a certain concentration of dye, dye removal decreases as the concentration increases.

\subsection{Effect of MW Radiation Time}

Fig. 6 shows the effect of the radiation time on dyestuff removal. It was found that the maximum removal percentage of the dyestuff was achieved in $3 \mathrm{~min}$ for both MB and AB. In the process of MW with adsorbent (catalyst), adsorbent surface absorbs MW and speed-up the degradation of dyestuff for rapid and effective removal. The most important feature of the microwave application is that the heating starts at the molecular level and penetrates into the substance to make the process more active and faster. 


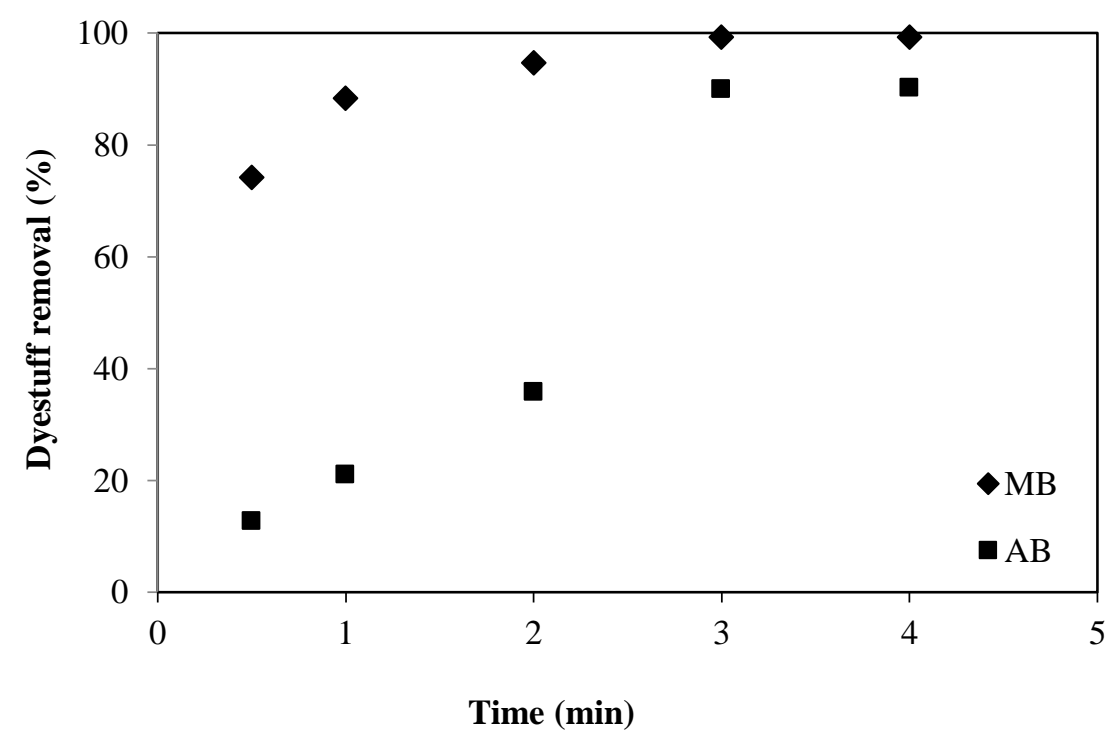

Figure 6. Effect of radiation time on removal with fixed amount of activated carbon and oxidant. (initial dye conc.: $100 \mathrm{mg} / \mathrm{L}$, adsorbent dosage: $0.5 \mathrm{~g}$ for $\mathrm{MB} ; 0.6 \mathrm{~g}$ for $\mathrm{AB}$, oxidant dosage:0.5 $\mathrm{mL}$ for $\mathrm{MB}$ and $\mathrm{AB})$.

\subsection{Removal of Dyestuff from Wastewater}

The effects of adsorbent dosage on dyestuff removal were investigated by addition of different amounts of adsorbent into $50 \mathrm{~mL}$ of wastewater. The results are shown in Figure 7.

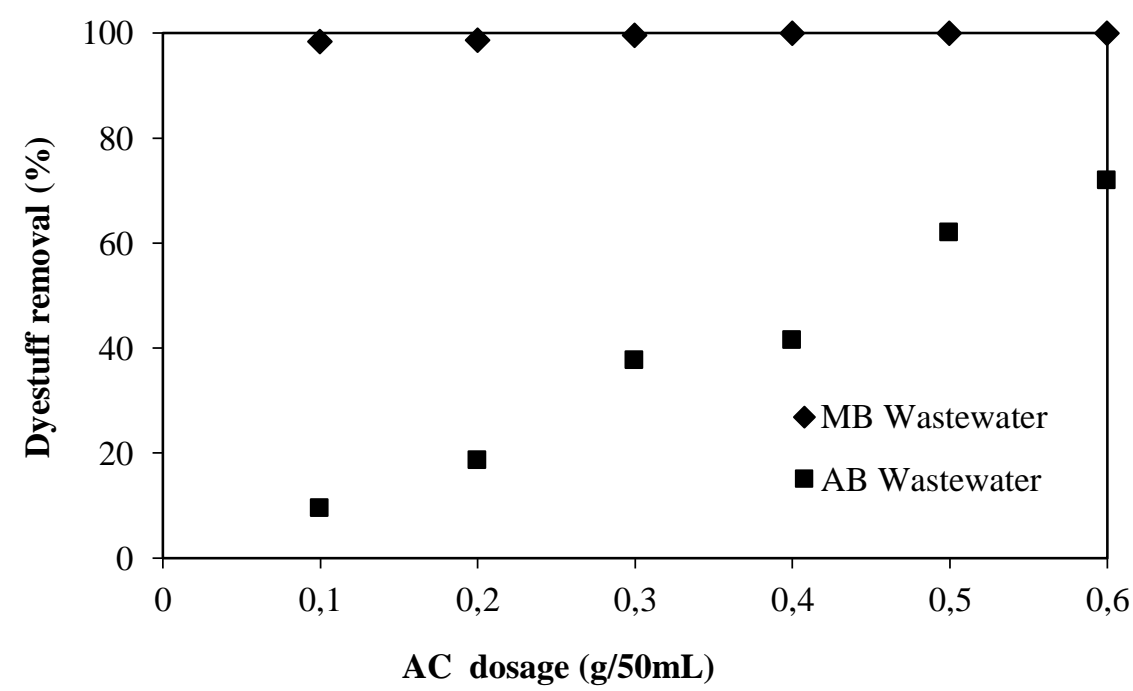

Figure 7. Effect of adsorbent dosage on dyestuff removal from wastewater with $0.5 \mathrm{~mL}$ oxidant. (radiation time: $3 \mathrm{ml}$, oxidant dosage: $0.5 \mathrm{~mL}$, initial dye conc: $100 \mathrm{mg} / \mathrm{L}$ )

It is evident that the removal efficiency (for MB) did not change significantly which is stable around $100 \%$. Whereas, the removal efficiency increased effectively for $\mathrm{AB}$ when the activated carbon dosage increased from $0.1 \mathrm{~g}$ to $0.6 \mathrm{~g}$. 


\section{Conclusion}

It can be concluded that the activated carbon produced from pumpkin seed by chemical activation is an effective and alternative adsorbent for the removal of methylene blue and acid blue 193 from aqueous solutions and wastewater because of its high surface area and high adsorption capacity. The prepared activated carbon has a high pore volume and a large BET surface area. It was found that the specific surface area and total pore volume of the activated carbon were $1564 \mathrm{~m}^{2} / \mathrm{g}$ and $0.965 \mathrm{~cm}^{3} / \mathrm{g}$, respectively. The microwave (MW) was a novel technique for wastewater treatment. The resultant carbons and oxidant were used to remove dyestuff from wastewater by MW radiation. In traditional heating methods, the heat is transmitted from the surface of the material to the interior. When compared with this method, the heating rate is high because the heat is produced in the material during the microwave heating and the processing time is short. The MW technology reduces the reaction time, decreases the activation energy, improves the reaction rate, reduces the equipment size and waste and increases the yield and purity of the products. With the initial dyestuff concentration of $100 \mathrm{mg} / \mathrm{L}$, dyestuff removal percentage was obtained as $99 \%$ at low power in $3 \mathrm{~min}$, using $0.5 \mathrm{~g}$ adsorbent and $0.5 \mathrm{~mL}$ hydrogen peroxide for $\mathrm{MB}$ and it was determined as $90 \%$ at low power in $3 \mathrm{~min}$, using $0.6 \mathrm{~g}$ adsorbent and $0.5 \mathrm{~mL}$ hydrogen peroxide for $\mathrm{AB}$. In this study, adsorption of $\mathrm{MB}$ and $\mathrm{AB}$ dyestuff on activated carbon was studied in order to compare the method of adsorption with microwave method. In the adsorption studies with $\mathrm{MB}$ and $\mathrm{AB}$, 95 and $35 \%$ dyestuff removals were obtained after 24 hours, respectively. By using the microwave method, a higher level of removal is achieved in a very short time.

\section{References}

Angın D., Köse T.E, Selengil U. (2013). Production and characterization of activated carbon prepared from safflower seed cake biochar and its ability to absorb Reactive Dyestuff. Appl. Surf. Sci. 280: 705-710.

Anton, D.C., Debrassi, A., Buzzi, F.C., Magro, J.D., Scapinello, J., Nedelko, N., ScapinelloWaniewska, A., Dluzewski, P., Rodrigues, C.A. (2016). Effect of microwave radiation on the adsorption of the dye remazol red 198 (rr198) by o-carboxymethylchitosan-n-lauryl/ $\mathrm{F}_{2} \mathrm{O}_{3}$ magnetic nanoparticles. Process Saf. Environ. Prot. 102: 392-402

Avelar, F.F., Bianchi, M.L., Gonçalves, M., Mota, E.G. (2010). The use of piassava fibers (attalea funifera) in the preparation of activated carbon. Bioresour. Technol. 101: 4639-4645.

Aygün, A., Yenisoy-Karakaş, S., Duman, I. (2003). Production of granular activated carbon from fruit stones and nutshells and evaluation of their physical, chemical and adsorption properties. Microporous Mesoporous Mater. 66: 189-195.

Banerjee, S., Chattopadhyaya, M.C., Srivastava. V., Sharma. Y.C. (2014). Adsorption studies of methylene blue onto activated saw dust: kinetics, equilibrium, and thermodynamic studies. Environ. Prog. Sustain. Energy. 33: 790-799.

Dehvari, M., Ehrampoush, M.H., Ghaneian, M.T., Jamshidi, B., Tabatabaee, M. (2017). Adsorption kinetics and equilibrium studies of reactive red 198 dye by cuttlefish bone powder. Iran. J. Chem. Chem. Eng.(IJCCE), 36(2): 143-151.

Demiral, H., Demiral, İ. (2008). Surface properties of activated carbon prepared from wastes. Surf. Interface Anal. 40: 612-615.

Demiral, İ., Aydın-Şamdan, C., Demiral, H. (2016). Production and characterization of activated carbons from pumpkin seed shell by chemical activation with $\mathrm{ZnCl}_{2}$. Desalin. Water Treat. 57(6): 2446-2454.

Demiral, H., Güngör, C. (2016). Adsorption of copper (II) from aqueous solutions on activated carbon prepared from grape bagasse. J. Clean. Prod. 124: 103-113.

76 | P a g e

www.iiste.org 
Faraji, H., Mohamadi, A.A., Soheil, Arezomand H.R., Mahvi, A.H. (2015). Kinetics and equilibrium studies of the removal of blue basic 41 and methylene blue from aqueous solution using Rice Stems. Iran. J. Chem. Chem. Eng.(IJCCE), 34(3): 33-42.

Gerçel, Ö., Özcan, A., Özcan, A.S., Gerçel, H.F. (2007). Preparation of activated carbon from a renewable bio-plant of euphorbia rigida by $\mathrm{H}_{2} \mathrm{SO}_{4}$ activation and its adsorption behavior in aqueous solutions. Appl. Surf. Sci. 253: 4843-4852.

Guo, Y.P., Rockstraw, D.A. (2007). Activated carbons prepared from rice hull by one step phosphoric acid activation, Microporous Mesoporous Mater. 100: 12-19.

Jiang, T., Zhang, Q., Liu, Y., Xue, X., Duan, P. (2016). Influence of microwave irradiation on boron concentrate activation with an emphasis on surface properties. Appl. Surf. Sci. 385: 88-98.

Kılıç, M., Apaydin-Varol, E., Pütün, A.E. (2011). Adsorptive removal of phenol from aqueous solutions on activated carbon prepared from tobacco residues: equilibrium, kinetics and thermodynamics. J. Hazard. Mater. 189: 397-403.

Lai, T.L., Lee, C.C., Wu, K.S., Shu, Y.Y., Wang, C.B. (2006). Microwave enhanced catalytic degradation of phenol over nickel oxide. Appl. Catal. 68: 147-153.

Li, N., Ma, X., Zha, Q., Kim, K., Chen, Y. (2011). Maximizing the number of oxygen-containing functional groups on activated carbon by using ammonium persulfate and improving the temperature-programmed desorption characterization of carbon surface chemistry. Carbon. 49: 5002-5013.

Lin, L., Chen, J., Xu, Z., Yuan, S., Cao, M., Liu, H., Lu, X. (2009). Removal of ammonia nitrogen in wastewater by microwave radiation: a pilot-scale study. J. Hazard. Mater. 168: 862-867.

Lin, L., Yuan, S., Chen, J., Wang, L., Wan, J., Lu, X. (2010). Treatment of chloramphenicol contaminated soil by microwave radiation. Chemosphere. 78: 66-71.

Morais, L.C., Freitas, O.M., Gonçalves, E.P., Vasconcelos, L.T., Gonzalez, Beça C.G. (1999). Reactive dyes removal from wastewaters by adsorption on eucalyptus bark: variables that define the process. Water Res. 33: 979-988.

Önal, Y., Akmil-Başar, C., Sarıcı-Özdemir, C., Erdoğan, S. (2007). Textural development of sugar beet bagasse activated with $\mathrm{ZnCl}_{2}$. J. Hazard. Mater. 142: 138-143.

Remya, N., Lin, J.G. (2011). Current status of microwave application in wastewater treatment- a review. Chem. Eng. J. 166: 797-813.

Tofighy, M.A., Mohammadi, T. (2014). Methylene blue adsorption onto granular activated carbon prepared from harmal seeds residue. Desalin. Water Treat. 52: 2643-2653.

Yang, J., Qiu, K. (2010). Preparation of activated carbons from walnut shells via vacuum chemical activation and their application for methylene blue removal, Chem. Eng. J. 165: 209-217.

Yorgun, S., Y1ldı, D. (2015). Preparation and characterization of activated carbons from paulownia wood by chemical activation with $\mathrm{H}_{3} \mathrm{PO}_{4}$. J. Taiwan Inst. Chem. Eng. 53: 122-131.

Wang, N., Wang, P. (2016). Study and application status of microwave in organic wastewater treatment- a review. Chem. Eng. J. 283: 193-214. 